\title{
Development of Dietary Guidelines for Persons undergoing Haemodialysis
}

\author{
Blessy Prabha Valsaraj ${ }^{1 *}$, P. Valsaraj ${ }^{2}$, Sripathy M Bhat ${ }^{3}$, Ravindra Prabhu $^{4}$ \\ Anice George 5 \\ 1.Associate Professor, Manipal College of Nursing Manipal, Manipal University, \\ 2.Associate Professor, Welcomgroup Graduate School of Hotel Administration, Manipal University, \\ 3.Professor, Dept. of Psychiatry, Kasturba Medical College, Manipal University, \\ 4.Professor and HoD of Nephrology, Kasturba Medical College, Manipal University, \\ 5.Dean, Manipal College of Nursing Manipal, Manipal University
}

\begin{abstract}
Food occupies the consciousness of all living beings and it is all the more prominent concern among individuals with chronic illness. This fact can be easily understood by analysing the content of most of the patients' queries to the health care professionals that are centered on dietary intake i.e. what food stuffs they can eat and which all they should avoid. As the result of many restrictions in their dietary intake, they feel a loss of control over life that can lead to poor life satisfaction and depression. Methods: A cross sectional survey was conducted among 50 chronic kidney failure patients those who are undergoing maintenance haemodialysis in the dialysis unit of Kasturba Hospital, using a purposive sampling technique. A semi structured interview schedule was used to assess their knowledge and practice of dietary intake. Results: None of the subjects had a clear view on actual renal diet and $40 \%$ believed there is no need of any dietary modifications, $100 \%$ believed it is difficult to adhere to dietary restrictions and only $78 \%$ practiced some kind of dietary modifications. Based on the identified need, dietary guideline for persons undergoing haemodialysis was developed and validated with the experts.
\end{abstract}

Key words: development, dietary guidelines, chronic kidney disease, persons undergoing haemodialysis

\section{Introduction:}

Chronic kidney disease (CKD) is becoming a major public health problem worldwide. CKD is the $12^{\text {th }}$ leading cause of death and $17^{\text {th }}$ cause of disability. ${ }^{1}$ Food plays avital rolein kidney rehabilitation and it is equally important like the regular dialysis for a person with CKD. Persons undergoing dialysis need to take adequate calories and higher amounts of protein to combat with the protein energy malnutrition due to regular haemodialysis. Since the kidney function is compromised it can no longer regulate the balance of minerals, vitamins and fluid, hence the diet needs to be low in potassium, phosphorus, sodium and fluid.

Common complications of CKD include vitamin deficiencies and electrolyte imbalances such as hyperkalemia, hyperphosphatemia and hypermagnesemia. Potassium is found high in many of the fruits including jack fruit, mango, musambi, orange, papaya, pomegranate, sapota and vegetables including papaya, bananas, and potatoes, Bitter gourd, brinjal, bamboo shoot, cabbage, drumstick, long beans, ladies finger and mushroom. Phosphateis found in such foods as nuts, dairy products, legumes, and meat) and magnesium (found in many vitamin and mineral supplements and medications, such as antacids and laxatives). Individualized diet counselling is essential for each of the clients based on their level of kidney function, lifestyle, culture, religion, financial status, comorbid conditions (diabetes, hypertension, hyperparathyroidism), treatment goals and biochemical parameters.

Non-adherence with the dietary regulations can result in chronically elevated serum levels of phosphate, which play an important role in the development of secondary hyperparathyroidism and renal osteodystrophy. ${ }^{2}$ Hyperkalemia can cause dangerous arrhythmias, elevated levels of phosphate also may increase coronary artery disease, even in young patients, ${ }^{3}$ leading to a significantly increased risk for mortality. ${ }^{4,5}$

Zrinyi et al in their cross sectional study of 107 haemodialysis patients from 20 dialysis centres in Geneva, reported that the patients with increased dietary self-efficacy had lower serum potassium and weight gain, showed more favourable compliance attitudes andbehaviours toward prescribed regimens and fosteredbetter relationships with staff. ${ }^{6}$ This shows that the persons with adequate knowledge are likely to have favourable attitude towards the dialysis treatment and diet and adopt correct ways of dietary adherence that can have a direct positive impact in the longevity of the person. 
Aim: To develop dietary guidelines for patients diagnosed with CKD and undergoing haemodialysis with a view to incorporate it in the cognitive behaviour diary for the subjects.

\section{Materials and Methods:}

A cross sectional survey was conducted among 50 CKD patients undergoing haemodialysis in the Dialysis unit of Kasturba Hospital as the first step of need assessment before the development of dietary guidelines. The sample were selected based on purposive sampling technique after getting the administrative permission, ethical clearance from the Hospital and informed consent from the participants. Those sample who were in the age between 20 to 60 years, who have started with maintenance dialysis as the mode of treatment for CKD for period more than six months, who can understand and speak English or Kannada and who are willing to participate in the study were included in the study. Those who have diabetic retinopathy, delirium, psychiatric illness or who were critically ill were excluded from the study.

The data was collected using a Background Proforma and a Semi-structured Interview Schedule on Dietary Knowledge and Practice. The instruments were validated by five experts from the field of medical surgical nursing, dietetics and nephrology. After establishing the content validity, the tools were translated to Kannada and retranslated to English by language experts and no modifications were brought in the Kannada tool further as it was matching with the original.

III. Results

Table1: Frequency and percentage distribution of sample characteristics

\begin{tabular}{|c|c|c|}
\hline Sample characteristics & Frequency & Percentage \\
\hline \multicolumn{3}{|l|}{ Age in years } \\
\hline $20-30$ & 8 & 16 \\
\hline $31-40$ & 8 & 16 \\
\hline $41-50$ & 16 & 32 \\
\hline $51-60$ & 18 & 36 \\
\hline \multicolumn{3}{|l|}{ Gender } \\
\hline Male & 36 & 72 \\
\hline Female & 14 & 28 \\
\hline \multicolumn{3}{|l|}{ Education } \\
\hline Primary School & 8 & 16 \\
\hline Secondary School & 14 & 28 \\
\hline Pre-degree & 15 & 30 \\
\hline Diploma/Graduation & 13 & 26 \\
\hline \multicolumn{3}{|l|}{ Religion } \\
\hline Hindu & 39 & 78 \\
\hline Christian & 9 & 18 \\
\hline Muslim & 2 & 4 \\
\hline \multicolumn{3}{|l|}{ Duration of haemodialysis } \\
\hline 6 months - 2 years & 28 & 56 \\
\hline 2 years one month -4 years & 20 & 40 \\
\hline$>4$ years & 2 & 4 \\
\hline
\end{tabular}

Table 1 shows that maximum sample (36\%) belonged to age ranging between 51 to 60 years and qualified Predegree $(30 \%)$. Majority were males (72\%) and Hindus (78\%). Most of them (56\%) started with haemodialysis since six months to two years.

Table2: Description of knowledge and practice on dietary intake in frequency and percentage

\begin{tabular}{|c|c|c|c|c|}
\hline \multirow{2}{*}{ Item } & \multicolumn{2}{|c|}{ Yes } & \multicolumn{2}{|c|}{ No } \\
\hline & $\mathbf{F}$ & $\%$ & $\mathbf{F}$ & $\%$ \\
\hline Do you have previous exposure to information on dietary modification? & 45 & 90 & 5 & 10 \\
\hline Have you consulted a dietician on the right kind of dietary intake? & 7 & 14 & 43 & 86 \\
\hline Have you modified your diet after starting dialysis? & 39 & 78 & 11 & 22 \\
\hline Do you think there is need of any dietary modifications & 20 & 40 & 30 & 60 \\
\hline Do you think that it is difficult to practice dietary modification? & 50 & 100 & 0 & 0 \\
\hline
\end{tabular}

The data presented in Table 2 show that majority of them (90\%) had some exposure to information regarding dietary modification and a few (14\%) have consulted dietician on the right kind of dietary intake. Only $78 \%$ of people undergoing haemodialysis have modified their diet after starting the treatment. Some of them $(40 \%)$ felt that there is actually no need for a strict diet modification as haemodialysis takes care of regulating the blood and all of them $(100 \%)$ said it is difficult to practice dietary modifications. When asked to describe the renal diet none of them were able to explain all the aspects of it whereas majority $(98 \%)$ of them 
were aware of the fruit restrictions and restriction of tender coconut water but instead of including the right fruit in their diet, most of them avoided all the fruits from their diet.

These results clearly indicated the need for developing dietary guidelines for the persons undergoing haemodialysis. The first draft of the same was prepared after review of literature and personal discussion with experienced nephrologists, dialysis technicians and dieticiansand based on their suggestions the final draft was prepared and validated by giving it to nine experts from the field of nephrology, dietetics, dialysis technology and medical surgical nursing. Some additions and deletions in the food lists were made (for example 'ragi manni' a porridge prepared with strained finger millet cooked with milk and jaggery, was removed because of its high potassium content) and food items of similar category were grouped under known food groups for easy selection and use as per the suggestion given from professor of dietetics and the final list of food items that can be taken and avoided is given in the table 3 .

Table:3 Food items that are to be taken and avoided by Haemodialysis patients

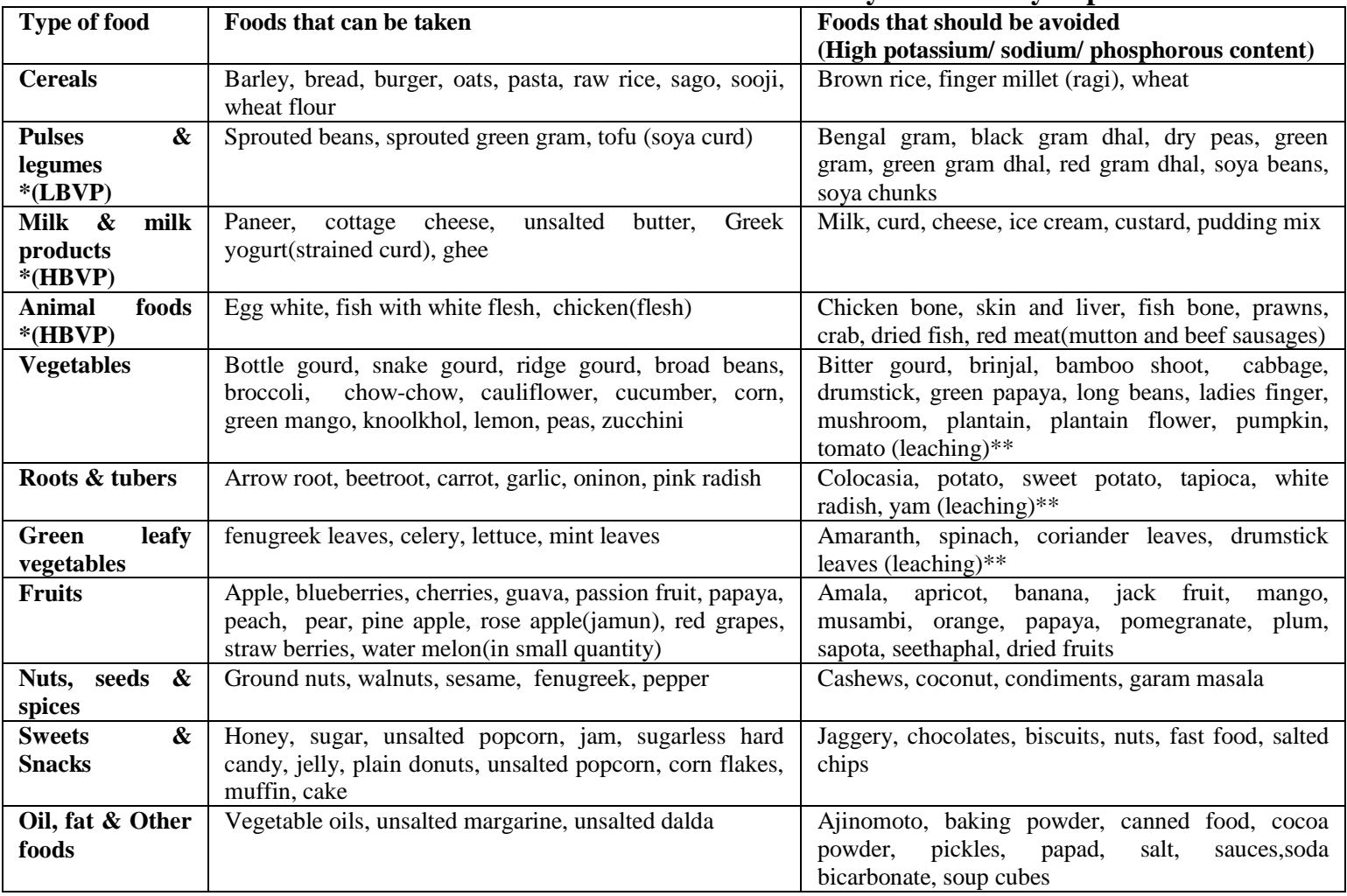

*HBVP: High biological value protein, *LBVP: Low biological value protein

**Leaching: The vegetables with high potassium can be consumed after leaching. It is done for removing the excess potassium in the vegetables.

\section{Diet Adherence Tips for Haemodialysis patients}

1. Take a diet that is low in potassium, phosphorous and sodium. Stick on to the foods given in the first column to remain healthy.

2. Read food labels in the packets so that you can avoid high potassium, phosphorous and sodium containing foods.

3. Protein will help to replace muscles and other tissues that you lose during dialysis, the $50 \%$ of total protein intake should be met by high biological value protein. So include it in small quantity (1gm per Kg body weight or 30-40 grams every day).

4. Take two egg whites three hours before dialysis.

5. Avoid salt and instead use other ingredients such as mint leaves, ginger, garlic, pepper and lemon to flavor foods.

6. All these food items contain potassium, phosphorous and sodium in small quantity, so take all type of foods in moderate quantity.

7. Expose to sunlight. (Get Vitamin D for better Calcium absorption and healthy bones).

8. Cook one spoon fenugreek seeds with rice for evening meal every night, in order to increase the hemoglobin. 
9. The vegetables with high potassium can be eaten after leaching. It is done for removing the excess potassium in the vegetables. (Method of leaching: Peal the vegetables and cut into pieces. Soak in warm water for two hours before cooking. Discard the soaked water and cook in a large volume of fresh water.)**

10. If you are a diabetic, avoid sugar, honey, cake, fruits from the list of foods that can be taken.

11. Unsalted margarine, dalda and other fats to be restricted in case of high cholesterol or blood pressure.

The table of food items and the diet adherence tips ${ }^{7-12}$ were incorporated in the booklet for the persons undergoing haemodialysis and also they were given with a teaching session on the dietary modifications required, with the help of power point presentation. Family members also were requested to attend the teaching session as the diet selection, preparation and diet adherence are family decisions than individual in traditional Indian society. The dietary guidelines were incorporated in the cognitive behavioural therapy and the entire sample along with the family felt that it is highly important to know the correct dietary guidelines.

\section{Discussion}

The present study found that majority of them $(90 \%)$ had some exposure to information regarding dietary modification and a few (14\%) have consulted dietician on the right kind of dietary intake. Only $78 \%$ of people undergoing haemodialysis have modified their diet after starting the treatment. A study conducted at Hospital of Madrid, among CKD patients reported that $77.74 \%$ of them had good knowledge and perception regarding renal diet and $35.77 \%$ altered dietary behavior when environmental conditions change. Almost half of the patients $(48.76 \%)$ expressed that renal protection diet represent a variation in their dietary habits. Most of them (56.79) reported that the diet was not been explained to them. ${ }^{13}$. The subjects verbalized guilt for exacerbating and advancing their kidney failure due to the practice of faulty dietary habits. ${ }^{14,15}$ Clarkson and Robinson in their qualitative study, reported gaps in the healthcare service wherein subjects lacked adequate information on health care that worsened health. ${ }^{16}$

The present study identified that that $40 \%$ of the persons undergoing haemodialysis felt that there is actually no need for a strict diet modification as haemodialysis takes care of regulating the blood and all of them $(100 \%)$ said it is difficult to practice dietary modifications. Two qualitative studies have earlier identified their absolute dietary dissatisfaction especially the salt restriction as expressed with statements such as "nobody wants to eat a tasteless food without salt." 14,15

In the current study none of the persons undergoing dialysis were able to explain all the aspects of renal diet whereas majority $(98 \%)$ of them were partially aware of only the fruit restrictions and thus the researchers took up development of dietary guidelines. Earlier researchers also have undertaken similar works and prepared learning materials for homecare for the same population at different periods. ${ }^{17,18} \mathrm{~A}$ systematic review of randomized trials carried out by Mason, Khunti, Stone, Farooqi and Carr identified 22 studies involving wide range of multicomponent interventions with variable aims and outcomes depending on the area of kidney disease care. $^{19}$

While teaching the persons undergoing haemodialysis and the family members, it was understood that individualized dietary education and modification is useful for them as they can clarify their doubts based on their dietary patterns, habits and likes. Many were vegetarians and they were suggested to increase other protein sources such as Greek yogurts, tofu (soya curd), mutter and sprouted green gram.

Fenugreek seeds are found to have a protective mechanism against of the peroxidation of lipid (LPO) membrane and cholesterol metabolism in the brain of rats, which may be attributed in part to its modulatory effect on plasmatic lipid metabolism. ${ }^{20}$ Anaemia is one among the most common problems faced by the persons undergoing haemodialysis. Fenugreek seeds and leaves also said to have properties of enhancing haemoglobin levels and ideal for the persons undergoing haemodialysis as they contain less potassium compared to other iron rich foods such as finger millet, bitter guard, spinach, drumstick leaves etc. Different forms of fenugreek ingestion was suggested to them such as soaking few spoons along with rice and urda dal while making dosa/idli, soaking overnight and having it in the next morning etc. It was agreeable for them to make fenugreek leaves along with sprouted green gram or soaked potatoes as side dish for rice or chappathi.

Another issue among this population is protein loss through dialysis, resulting in fatigue, weight loss and lethargy. Thus recommended dietary modification contains intake of 1.5 grams of high biological value protein (60\% of HBVP) per kilogram body weight in haemodialysis. Egg white is a rich source of HBPV and thus suggested them to have two egg whites four to five hours prior to dialysis, considering the time required for 
digestion. Many of them found omelet prepared with two egg whites as a better option than taking the boiled egg white.

\section{Conclusion:}

It is definitely possible for the CKD patients to support their kidneys by following the renal diet. There is a high need for dietary education for the persons undergoing haemodialysis as well as their family members. Nurses maintain a close relation with the people undergoing maintenance dialysis and in better position to guide them with the right kind of diet. The nurses need to extend their support by providing needed education, motivation and psychological support towards this vital aspect of the treatment. The process of adaptation and maintenance to a healthy new dietary habit requires constant support, follow up and reinforcement.

\section{Acknowledgements}

We express sincere gratitude to Dr. Tessy Treesa Jose and Dr. Linu sara George, Professors of Manipal College of Nursing Manipal, Dietetics experts, dialysis staff and persons undergoing haemodialysis for their valuable support and co-operation.

\section{Reference:}

[1]. World Health Organisation. Burden of disease project available at: http://www.3.who_int/whosis/menu.cfm?path= evidence, burden \& language accessed on August 2007.

[2]. Schneider B. Multidimensional health locus of control as partial predictor of serum phosphorus in chronic haemodialysis. Psychol Rep. 1992;70:1171-1174.

[3]. Goodman WG. Vascular calcification in end-stage renal disease. J Nephrol. 2002;15(suppl 6):S82-S85.

[4]. Leggat JE Jr, Orzol SM, Hulbert-Shearon TE, et al. Noncompliance in haemodialysis: predictors and survival analysis. Am J Kidney Dis. 1998;32:139-145

[5]. Block GA, Klassen PS, Lazarus JM, Ofsthun N, Lowrie EG, Chertow GM. Mineral metabolism, mortality, and morbidity in maintenance haemodialysis. J Am SocNephrol. 2004;15:2208-2218.

[6]. Zrinyi M, Juhasz M, Balla J, Katona E, Ben T, Kakuk G and Pall D. Dietary self-efficacy: determinant of compliance behaviours and biochemical outcomes in haemodialysis patientsNephrol Dial Transplant 2003;18:1869-1873

[7]. Johns S, Jenifer DJ. Essentials of nutrition and dietetics for nursing. New Delhi: BI Publications Pvt Ltd; 2007.

[8]. Diet - chronic kidney disease. Available from: http://www.nlm.nih.gov/medlineplus/ency/article/002442.htm

[9]. Renal diet guide. Dietary department, KMC Hospital, Attavar, Mangalore.

[10]. CapicchianoD. Top 7 tips for a healthy renal diet. Available from: http://www.kidneycoach.com/1089/renal-diet-top-7-tips-for-renalfailure/

[11]. Byham-Gray LD, Burrowes JD, Chertow GM. Nutrition in kidney disease. New Delhi: Springer Science; 2010

[12]. Potassium and chronic kidney disease. Available from: http://www.davita.com/kidney-disease/diet-and-nutrition/dietbasics/potassium-and-chronic-kidney-disease/e/5308

[13]. Villanueva OMT, Cisneros RA, Ruiz ME, Rincon MC. Determination of factors conditioning adherence and accomplishment of renal protection diet in patients with chronic renal failure: pilot study for the elaboration of a dietary guideline. Nutr Hosp. 2006 MarApr;21(2):145-54

[14]. Sheiba D. A qualitative analysis of the impact of end stage renal disease on the lived experience of dialysis patients and their spouses from a selected hospital Madurai. Unpublished dissertation submitted to Manipal University, September 2002.

[15]. Valsaraj BP, Bhat SM, Prabhu R, Dinesh N. Lived experience of haemodialysis patients. Paper presented at: International Research Meet on Non Communicable Diseases organized by Departments of Medicine, Community medicine and Statistics of Manipal University; 2013

[16]. Clarkson KA, Robinson K. Life on dialysis: a lived experience. Nephrol Nur J 2010; 37: 29-35

[17]. Devi ES, Prabhu R, Bhanumathi PP, Sequiera L, Mayya SS, Bairy KL, Mohan MK. Identification of Health Problems of Patients Undergoing Haemodialysis Using Self Care Deficit Theory and Application of Nursing Process Approach Care. Internat $\mathbf{J}$ of NursEduc 4(1) Jan-June:15-17, 2012

[18]. Thomas M. An evaluative study to determine the effectiveness of a planned teaching programme about 'home care of patients with chronic renal failure' on chronic renal failure patients and their attendants, in a selected hospital, in Udupi district. Unpublished dissertation submitted to MAHE; 1999.

[19]. Mason J, Khunti K, Stone M, Farooqi A, Carr S. Educational Interventions in Kidney Disease Care: A Systematic Review of Randomized Trials. Am J Kidney Dis 51:933-951.

[20]. Nouira Y B, Bakhta H, Bouaziz M, Flehi-Slim I, Haouas Z and Cheikh H B. Study of lipid profile and parieto-temporal lipid peroxidation in $\mathrm{AlCl} 3$ mediated neurotoxicity modulatory effect of fenugreek seeds. Lipids in Health and Disease 11:16; 2012 